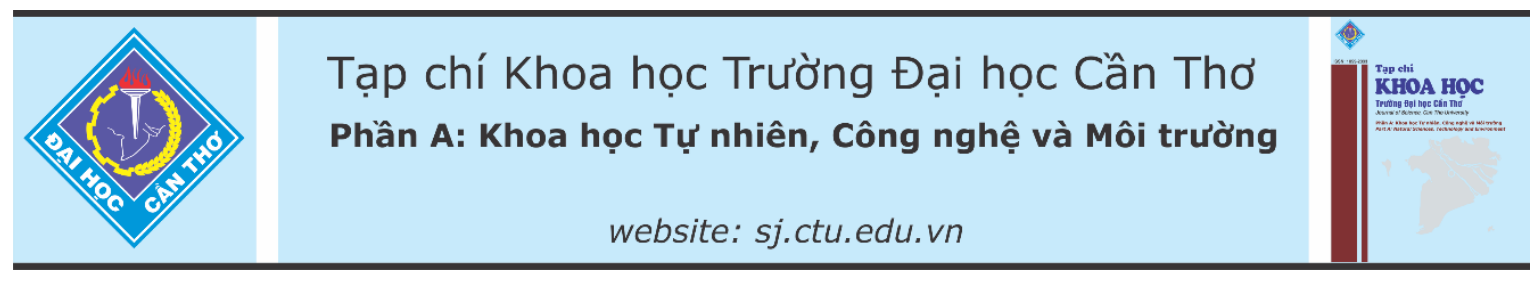

DOI:10.22144/ctu.jvn.2021.139

\title{
NGHIÊN CÚUU ÚNG DỤNG CÔNG NGHỆ ĐẤT NGẬP NƯỚC KIẾN TẠO SỬ DỤNG THỰC VẬT XỬ LÝ NGUỒN NƯớC MặT Ô NHIỄM
}

\author{
Nguyễn Minh Kỳ ${ }^{1 *}$, Nguyễn Công Mạnh ${ }^{2}$, Phan Văn Minh ${ }^{2}$, Nguyễn Tri Quang Hưng ${ }^{1}$ và \\ Phan Thái Sơn ${ }^{3}$ \\ ${ }^{1}$ Khoa Môi truòng và Tài nguyên, Truò̀ng Đại học Nông Lâm thành phố Hồ Chí Minh \\ ${ }^{2}$ Trung tâm Nghiên cứu Công nghệ môi truờng và Quản lý Tài nguyên thiên nhiên, Truờng Đại học Nông \\ Lâm thành phố Hồ Chí Minh \\ ${ }^{3}$ Viện Môi truờng và Tài nguyên, Đại học Quốc gia thành phố Hồ Chí Minh \\ *Người chịu trách nhiệm về bài viết: Nguyễn Minh Kỳ (email: nmky@hcmuaf.edu.vn)
}

\section{Thông tin chung:}

Ngày nhận bài: 16/03/2019

Ngày nhận bài sưa: 17/07/2021

Ngày duyệt đăng: 29/10/2021

Title:

Application of constructed wetlands technology with common grasses to remove pollutants from surface water

\section{Tù khóa:}

Cỏ sậy, đất ngập nuơóc kiến tao, nước mặt, ô nhiếm, vertiver

\section{Keywords:}

Constructed wetlands, Phragmites australis L., pollution, surface water, Vertiveria zizanioides $L$.

\begin{abstract}
The vertical flow constructed wetlands were conducted in order to remove pollutants from surface water for agricultural purposes. Two studied factors were selected involving the common plants: Phragmites australis L. and Vertiveria zizanioides L., and hydraulic loading rates of 500, 100 and $1500 \mathrm{~mL} / \mathrm{min} / \mathrm{m}^{2}$, respectively. Studying results showed that the constructed wetlands with hydraulic loading rate of 500 $\mathrm{mL} / \mathrm{min} / \mathrm{m}^{2}$ had obtained the most effective removal: $\mathrm{BOD}_{5}$ in the effluent was $10.6 \pm 0.8 \mathrm{mg} / \mathrm{L}$ and average removal efficiency of $94.4 \pm 0.4 \%$; COD was $24.3 \pm 2.7$ $\mathrm{mg} / \mathrm{L}$ and average removal efficiency of $90.6 \pm 0.8 \%$; TSS was 23.6 $0.2 \mathrm{mg} / \mathrm{L}$ and average removal efficiency of $84.4 \pm 0.6 \%$. Statistical analysis techniques also showed that the average $B O D_{5}, C O D$, TSS reduction among the experient plants were not different $(P>0.05)$. However, the data illustrated that the grasses factor had a positive effect on the removal efficiency related to fecal coliform. The factor of hydraulic loading rate, besides, there were statistically significant effects on the removal efficiency of $B O D 5, C O D, T S S$ levels $(P<0.05)$. Therefore, the studying model showed the compatibility with the environmentally friendly trend and could contribute to promoting sustainable agricultural development.
\end{abstract}

\section{TÓM TẮT}

Nghiên cưu ứng dụng công nghệ đất ngập nước kiến tạo có dòng chảy đứng để xủ lý nguồn nước mặt ô nhiếm kênh D ở thị xã Thuận An phuc vu canh tác nông nghiệp đã được tiến hành. Hai yếu tố tác động đã được nghiên cúu gồm (1) cây trồng và (2) tải nạp thủy lục. Cỏ sậy (Phragmites australis L.) và cỏ vertiver (Vertiveria zizanioides L.) được sư dụng trong nghiên cưu với đối chưng là không trồng cây. Các tải nạp thủy lực được thư nghiệm lần luoơt gồm 500, 1000 và $1500 \mathrm{~mL} / \mathrm{phu}^{\mathrm{t}} / \mathrm{m}^{2}$. Kết quả nghiên cứu cho thấy công nghệ đất ngập nước kiến tạo với mức tải nạp thủy lực 500 $\mathrm{mL} /$ phút $/ \mathrm{m}^{2}$ có hiệu quả xủ lý tốt nhất với lần luợt: hàm luợng $B O D_{5}$ của nước sau

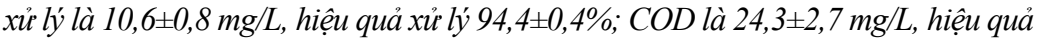

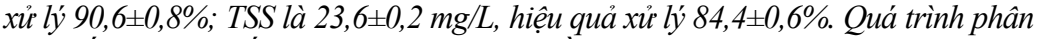
tích thống kê cho thấy không có sụ khác biệt về hiệu quả xủ lý $B O D_{5}, C O D$, TSS giũa các loại cây trồng $(P>0,05)$. Tuy nhiên, mức độ loại bỏ thông số vi sinh fecal coliform chỉ ra tác động tích cực của các loại cây trồng trong mô hình đất ngập nước kiến tạo. Trong khi đó, yếu tố tải nạp thủy lực có tác động rõ rệt đến hiệu quả xủ lý $B O D_{5}$, $C O D, T S S(P<0,05)$. Tù đó cho thấy mô hìn nghiên cứu phù hơp với xu hướng thân thiện môi trường và đáp úng nhu cầu phát triển nông nghiệp bền vũng. 


\section{1. ĐẶT VẤN ĐỀ}

Công nghệ đất ngập nước kiến tạo được biết đến là giải pháp công nghệ xử lý nước thải đạt hiệu quả (ElZein et al., 2016). Về cấu trúc, đây là hệ thống tổng hợp và phức tạp gồm các thành phần của nước, hệ động thực vật, vi sinh vật và điều kiện môi trường. Mô hình đất ngập nước kiến tạo là công nghệ có nhiều ưu điểm như chi phí xây dựng, duy tu, bảo dưỡng thấp, phương pháp xử lý thân thiện với môi trường (Kadlec \& Wallace, 2009). Theo hệ thống phân loại, công nghệ đất ngập nước kiến tạo bao gồm các loại như dòng chảy mặt tự do, dòng chảy ngầm theo phương ngang và dòng chảy ngầm theo phương đứng (Vymazal, 2010). Hơn nữa, chúng áp dụng quá trình xử lý dựa trên các nguyên lý tương tác sinh thái giữa các cấu phần đã được sắp xếp trong cùng một hệ sinh thái thủy vực. Công nghệ đất ngập nước được chứng minh về khả năng xử lý nước thải đô thị, sinh hoạt, công nghiệp, nước rỉ rác, nước thải chăn nuôi, nuôi trồng thủy sản,... (Dallas et al., 2004; Katarzyna \& Magdalena, 2017; Lê Diễm Kiều và ctv., 2018; Lê Hoàng Việt và ctv., 2017; Phạm Ngọc Hoà, 2018; Vymazal, 2009). Trong đó, cỏ vertiver đã được nhiều sự quan tâm nghiên cứu ứng dụng xử lý các loại nước ô nhiễm khác nhau (Datta et al., 2013; Dudai et al., 2006; Lu et al., 2004; Roongtanakiat \& Chairoj, 2001; Seroja et al., 2018; Truong et al., 2010). Tương tự, cỏ sậy cũng là đối tượng sử dụng hiệu quả trong việc xử lý ô nhiễm nước và bảo vệ môi trường (Aboubacar et al., 2018; Abou-Elela \& Hellal, 2012; Havens et al., 2003; Mirco \& Attilio, 2013).

Thị xã Thuận An có diện tích tự nhiên 82,46 $\mathrm{km}^{2}$, dân số 361640 người, mật độ dân số trung bình 4386 người $/ \mathrm{km}^{2}$, nằm trong vùng kinh tế trọng điểm phía Nam. Đây là khu vực năng động, có tốc độ phát triển kinh tế xã hội cao của tỉnh Bình Dương. Tuy nhiên, thực tế hoạt động kiểm soát ô nhiễm nước luôn gặp phải những khó khăn, thách thức (Nguyễn
Hoàng Ánh và ctv., 2014) và cần nâng cao hơn nữa nhận thức của người dân trong các hoạt động sản xuất bao gồm cả nông nghiệp (Nguyễn Trần Khánh và ctv., 2015). Với sự tập trung nhiều khu công nghiệp, dân cư đã thải ra một lượng nước thải công nghiệp và sinh hoạt đe dọa môi trường và các hệ sinh thái thủy vực. Hoạt động nghiên cứu đánh giá hiện trạng môi trường và đề ra giải pháp cải thiện hết sức quan trọng (Nguyễn Mạnh Khải và ctv., 2012). Mặt khác, khả năng tiêu thoát nước kênh rạch bị hạn chế, nguồn nước sử dụng cho nông nghiệp ngày càng cạn kiệt, không đáp ứng nhu cầu tưới tiêu cũng như hoạt động nuôi trồng thủy sản. Việc ứng dụng mô hình đất ngập nước kiến tạo nhằm tái sử dụng nước cho mục đích tưới tiêu nhận được nhiều sự quan tâm (Almuktar et al., 2018; Marecos \& Albuquerque, 2010; Maurizio et al., 2001) và được xem là giải pháp thay thế bền vững (Licata et al., 2017). Trước vấn đề thực tiễn, câu hỏi đặt ra là phải tìm ra công nghệ có chi phí phù hợp để xử lý nước mặt phục vụ canh tác nông nghiệp. Xuất phát từ đó, việc nghiên cứu áp dụng công nghệ thân thiện môi trường như mô hình đất ngập nước kiến tạo rất cần thiết. Mục đích nghiên cứu nhằm xem xét khả năng xử lý các chất ô nhiễm nguồn nước mặt bằng công nghệ đất ngập nước sử dụng hệ thực vật để phục vụ tưới tiêu nông nghiệp.

\section{PHƯƠNG PHÁP NGHIÊN CỨU}

\section{1. Đối tượng nghiên cứu}

Nguồn nước mặt dùng trong nghiên cứu là nguồn nước của kênh $\mathrm{D}$ thuộc thị xã Thuận An, tỉnh Bình Dương. Kênh D nhận nước thải từ khu dân cư Areco và khu công nghiệp Đồng An. Chất lượng nước của kênh $\mathrm{D}$ bị ô nhiễm nặng bởi các chất thải hữu cơ, vi sinh và không đạt chuẩn dùng cho tưới tiêu nông nghiệp theo Quy chuẩn QCVN 08MT:2015/BTNMT. Đặc điểm tính chất, chất lượng nguồn nước trước xử lý trong các thí nghiệm được trình bày trong Bảng 1 .

Bảng 1. Đặc tính của chất lượng nguồn nước trước xử lý ( $\left.{ }^{\mathrm{a}}\right)$

\begin{tabular}{lrrrr}
\hline \multirow{2}{*}{ Thí nghiệm } & \multicolumn{4}{c}{ Thông số chất lượng nước } \\
\cline { 2 - 5 } & BOD $\mathbf{~ ( m g / L ) ~}$ & COD (mg/L) & TSS (mg/L) & $\begin{array}{r}\text { Fecal coliform } \\
\text { (MPN/100mL) }\end{array}$ \\
\hline Tải nạp 1 & $139 \pm 5$ & $204 \pm 7$ & $161 \pm 12$ & $8055 \pm 3564$ \\
Tải nạp 2 & $121 \pm 41$ & $234 \pm 78$ & $93 \pm 33$ & $11085 \pm 2919$ \\
Tải nạp 3 & $146 \pm 39$ & $276 \pm 9$ & $136 \pm 31$ & $11725 \pm 5589$ \\
Quy chuẩn 08-MT:2015 (B1) & 15 & 30 & 50 & - \\
\hline
\end{tabular}

Chú thích: (a) giá trị trung bình \pm độ lệch chuẩn; QCVN 08-MT:2015/BTNMT: Quy chuẩn kỹ thuật quốc gia về chất luợng nước mặt; Cột B1 - Dùng cho mục đích tưới tiêu, thủy lợi. 
Đối với hệ thực vật, dựa vào những kết quả của các nghiên cứu trước đây, loài sậy phổ biến Phragmites australis L. (Abou-Elela \& Hellal, 2012; Aboubacar et al., 2018; Havens et al., 2003; Mirco \& Attilio, 2013) và cỏ Vertiver với tên gọi
Vertiverria zizanioides L. (Badejo et al., 2018; Danh et al., 2009; Effendi et al., 2015; Indrayatie et al., 2013) đã được chọn lựa cho nghiên cứu. Việc chọn lựa các loài cỏ nhằm tạo điều kiện so sánh với các kết quả nghiên cứu trên thế giới về hiệu quả xử lý.

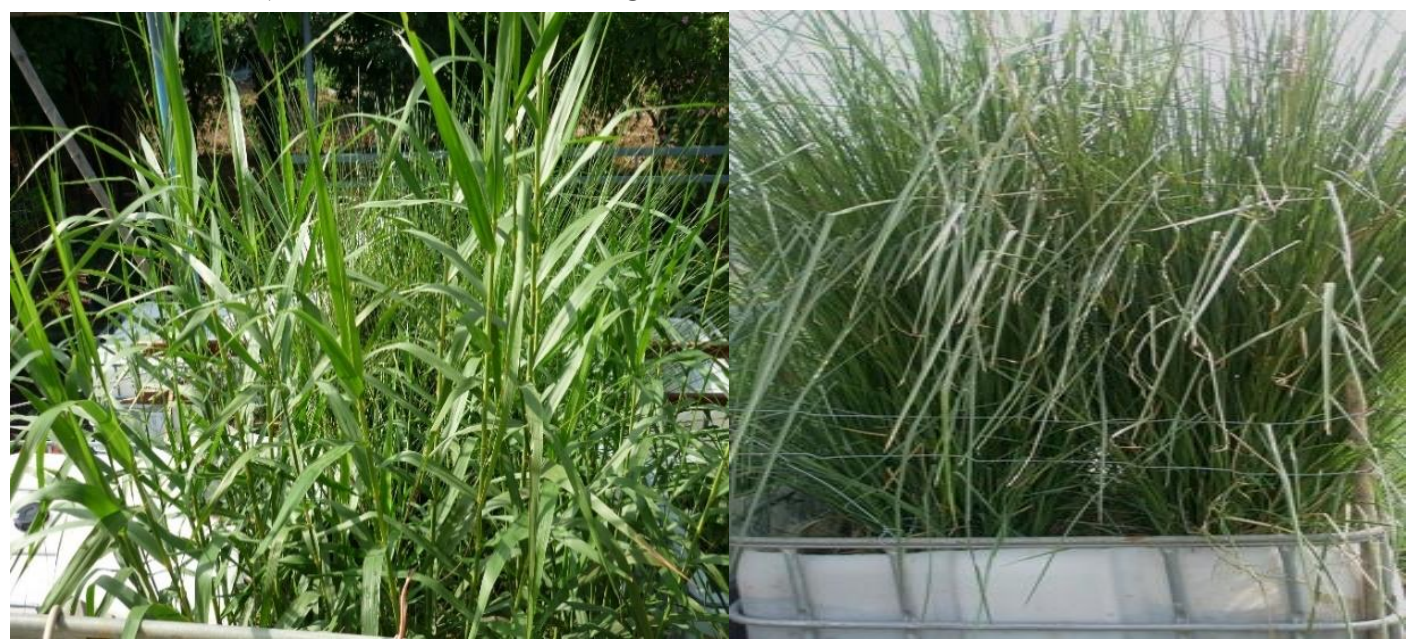

Hình 1. Cỏ Sậy (trái) và Vertiver (phải) trưởng thành

Cỏ được nhân giống trong Vườn sưu tập thủy sinh vật của Trường Đại học Nông Lâm. Những cây sậy và vertiver trưởng thành có thân chắc khoẻ với đường kính khoảng từ 0,5 đến $1 \mathrm{~cm}$ được chọn lọc. Sau đó cắt bỏ hết lá, cắt thành từng đoạn có chiều dài từ 40 đến $50 \mathrm{~cm}$ và có từ 4 đến 5 mắt để làm hom giống. Hom giống được chuyển sang khu vực ươm và ươm cho đến khi thành cây đã phát rễ và lá mới. Các cây mới sau đó được chuyển vào trồng trong các bể thí nghiệm để tiếp tục phát triển. Mật độ của sậy và vertiver được trồng trong các bể thí nghiệm là 20 cây $/ \mathrm{m}^{2}$. Thí nghiệm được tiến hành sau khi chúng đã được trồng 05 tháng - với chiều cao từ 0,6 đến $0,8 \mathrm{~m}$.

\subsection{Thiết kế thí nghiệm}

Nghiên cứu được bố trí theo thiết kế thí nghiệm yếu tố. Hai yếu tố được nghiên cứu là tải nạp thủy lực (lưu lượng tải nạp) và loại cây. Theo đó, tải nạp thủy lực gồm 3 mức $500 \mathrm{~mL} /$ phút $/ \mathrm{m}^{2}$ (T1), 1000

Bảng 2. Bố trí thí nghiệm nghiên cứu
$\mathrm{mL} /$ phút $/ \mathrm{m}^{2}(\mathrm{~T} 2)$ và $1500 \mathrm{~mL} /$ phút $/ \mathrm{m}^{2}(\mathrm{~T} 3)$; và loại cây gồm cỏ sậy, cỏ vertiver và không trồng cây (đối chứng). Các số mã hóa của các nghiệm thức thí nghiệm tương đương gồm:

- Tải nạp 1 (T1) ứng với Sậy (S1), Vertiver (V1) + Đối chứng không trồng cây $(\mathrm{C} 1)$.

- Tải nạp 2 (T2) ứng với Sậy (S2), Vertiver (V2) + Đối chứng không trồng cây (C2).

- Tải nạp 3 (T3) ứng với Sậy (S3), Vertiver (V3) + Đối chứng không trồng cây (C3).

Các nghiệm thức được bố trí theo phương pháp bố trí khối đầy đủ ngẫu nhiên và mỗi nghiệm thức 3 lần lặp lại có đối chứng (Bảng 2). Thí nghiệm được thiết kế vận hành với lưu lượng dòng chảy từ 30 đến $90 \mathrm{~L} / \mathrm{h}$, thời gian lưu thủy lực (HRT) từ 4,7 đến 14 giờ và tải lượng hữu cơ (OLR) tương đương 1000,8 đến $3153,6 \mathrm{~kg} \mathrm{BOD} /$ ha/ngày.

\begin{tabular}{lccc}
\hline Tải nạp thủy lực & Sậy (S) & Vertiver (V) & Không cây (C) \\
\hline Tải nạp 1 (T1) & S1 & V1 & C1 \\
Tải nạp 2 (T2) & S2 & V2 & C2 \\
Tải nạp 3 (T3) & S3 & V3 & C3 \\
\hline
\end{tabular}


Bảng 3. Thông số vận hành hệ thống thí nghiệm

\begin{tabular}{|c|c|c|c|c|}
\hline Ký hiệu & $\begin{array}{r}\text { Lưu lượng (Q, } \\
\mathrm{L} / \mathrm{h})\end{array}$ & $\begin{array}{l}\text { Thời gian lưu thủy } \\
\text { lục }(\text { HRT, } h)\end{array}$ & $\begin{array}{r}\text { Tải nạp thủy lực } \\
\left(\mathbf{m L} / \mathbf{p h u ́ t} / \mathbf{m}^{2}\right)\end{array}$ & $\begin{array}{r}\text { Tải lượng hữu co } \\
\text { (OLR, kg BOD } 5 / \text { ha/ngày) } \\
\end{array}$ \\
\hline T1 & 30 & 14,0 & 500 & 1000,8 \\
\hline $\mathrm{T} 2$ & 60 & 7,0 & 1000 & 1742,4 \\
\hline $\mathrm{T} 3$ & 90 & 4,7 & 1500 & 3153,6 \\
\hline
\end{tabular}

Bố tri hệ thống bể thi nghiệm: Nguồn nước được bơm lên bể chứa đặt ở độ cao $2,5 \mathrm{~m}$, cách mặt bể thí nghiệm 1,5 m. Nước sẽ chảy xuống các bể thí nghiệm thông qua các bơm định lượng

(MANOSTAT, USA) để thiết lập các tải nạp thủy lực/thời gian lưu nước tương ứng với các thí nghiệm. Sơ đồ bố trí dòng chảy được trình bày trong Hình 2.

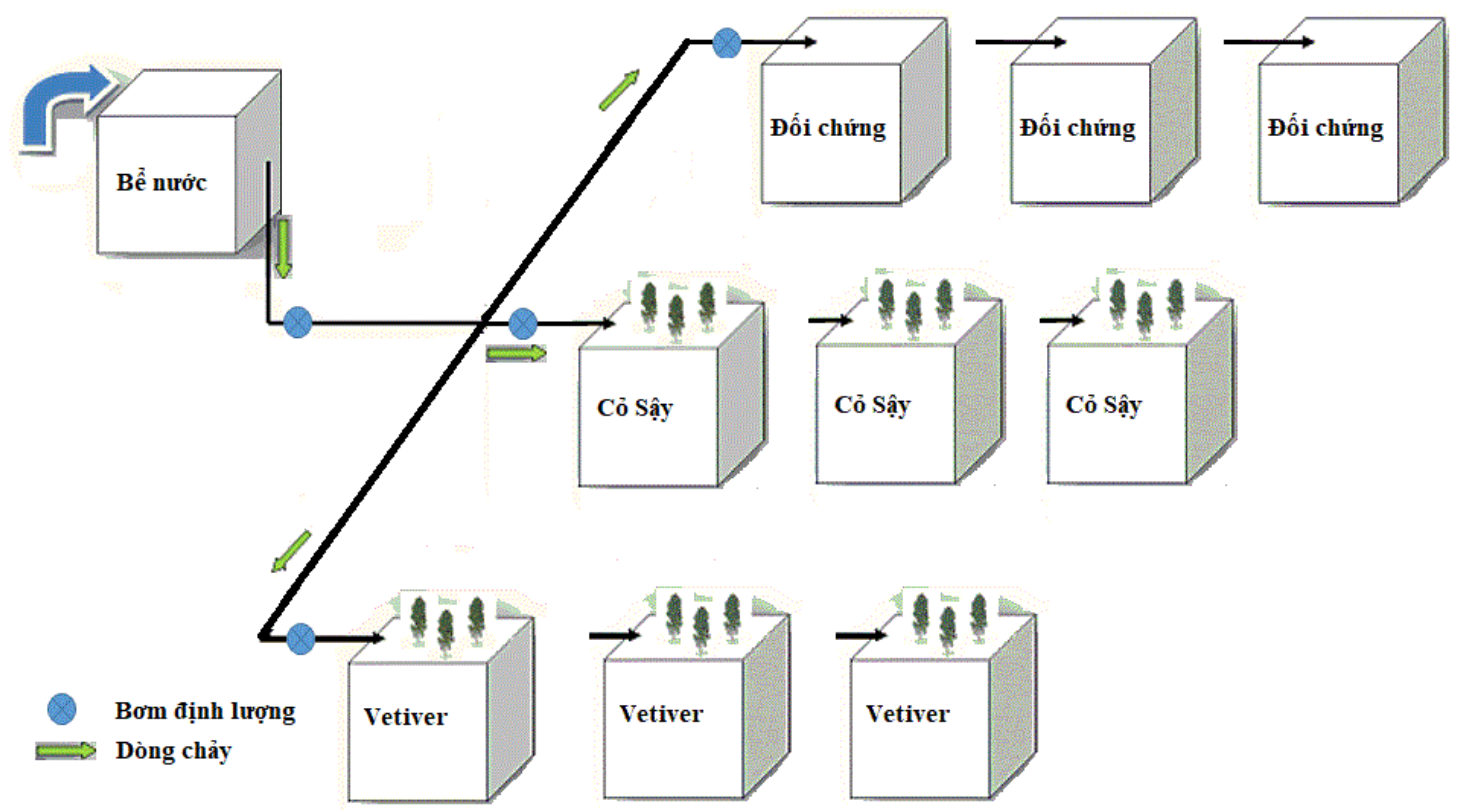

Hình 2. Sơ đồ hệ thống bể thí nghiệm

Hệ thống bể thí nghiệm: Hệ thống thí nghiệm gồm có các bể nhựa plastic, mỗi bể có dung tích $1000 \mathrm{~L}(1 \times 1 \times 1 \mathrm{~m})$ và được trồng 20 cây. Nước được phân phối xuống các bể thí nghiệm có chứa các lớp vật liệu lọc theo thứ tự: đá $4 \times 6 \mathrm{~cm}$ - dày $20 \mathrm{~cm}$, đá $1 \times 2 \mathrm{~cm}-$ dày $20 \mathrm{~cm}$, đá mi hạt lớn - dày $15 \mathrm{~cm}$, cát hạt lớn - dày $15 \mathrm{~cm}$. Độ rỗng của toàn khối vật liệu lọc tương ứng $40 \%$. Độ rỗng khối được xác định bằng cách đo lường lượng nước đi qua, xác định theo tỷ lệ giữa thể tích trống (khoảng trống các lỗ hổng giữa các lớp vật liệu) trên tổng thể tích (tổng thể tích thực không chứa các lớp vật liệu). Dòng chảy qua bể thí nghiệm là dòng chảy thẳng đứng. Các bể thí nghiệm được cấp nguồn nước thí nghiệm từ bể chứa đặt trên cao thông qua hệ thống hình xương cá đặt nằm trên mặt bể và được đục lỗ nhằm phân phối đều nước trên bề mặt các bể (Hình 3). Trong đó, ống phân phối nước được bố trí theo hình thức mạng lưới các đường song song với chiều dài khoảng cách các cạnh tương ứng $12 \mathrm{~cm}$. 


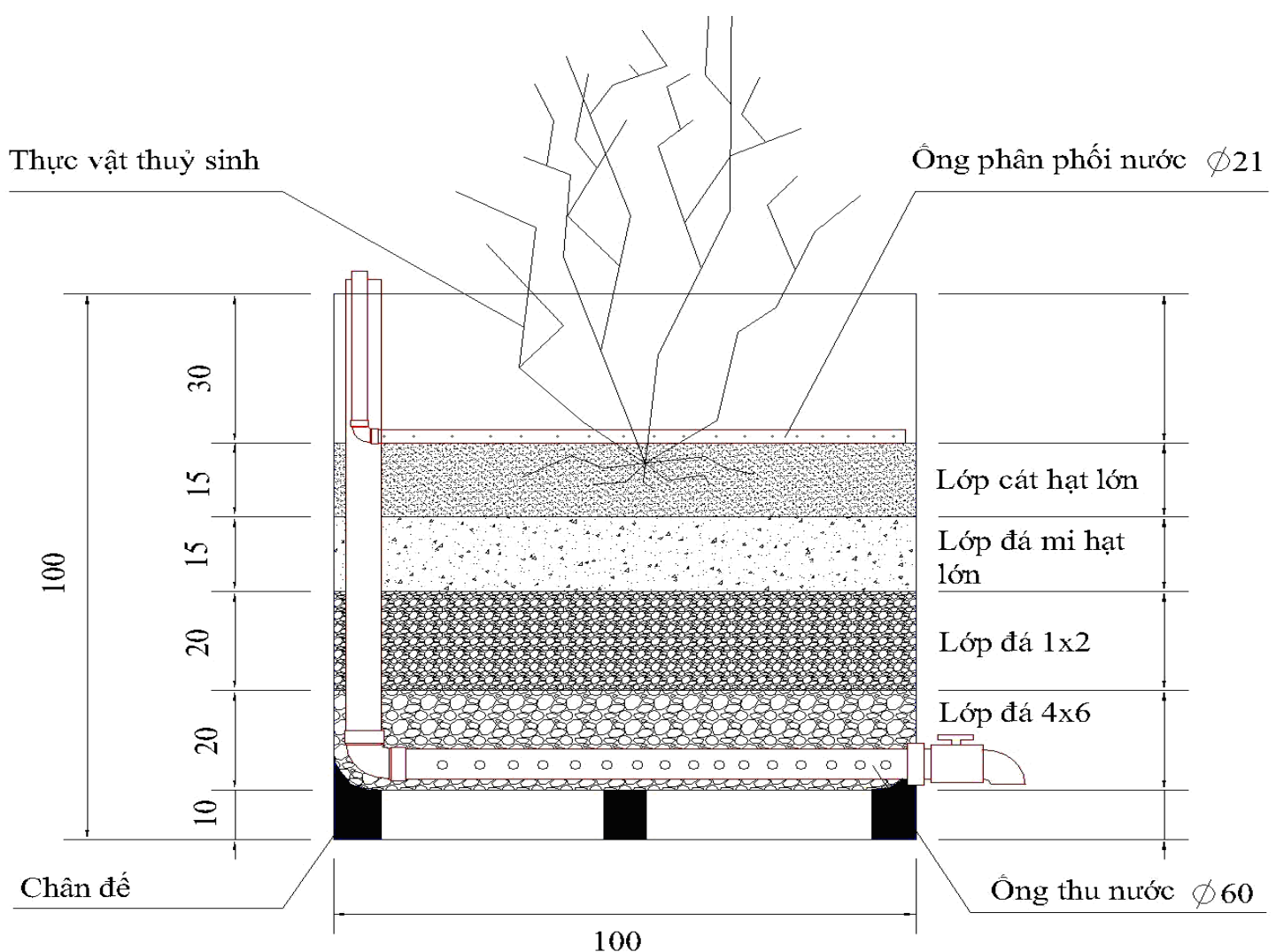

Hình 3. So đồ thiết kế bể thí nghiệm

\subsection{Phương pháp lấy mẫu và phân tích}

Mẫu nước đầu vào được lấy tại đầu vào của bể thí nghiệm và các mẫu đầu ra (sau xử lý) được thu tại đầu ra của bể thí nghiệm. Cụ thể, sau khi ổn định hệ thống 3 tuần, ở mỗi thí nghiệm tải nạp thủy lực, mẫu nước được lấy tại bể chứa nước đầu vào và bể chứa nước đầu ra sau quá trình xử lý thông qua hệ thống van xả. Các mẫu được tiến hành thu liên tục trong 10 tuần với tần suất thu mẫu 1 tuần/lần để đánh giá chất lượng và hiệu quả xử lý của hệ thống. Quá trình lấy mẫu được thực hiện theo TCVN 6663-
1:2011 Chất lượng nước - Lấy mẫu: Hướng dẫn lập chương trình lấy mẫu và Kỹ thuật lấy mẫu. Căn cứ vào mục đích xem xét hiệu quả xử lý các thành phần cơ bản, nghiên cứu chỉ tiến hành lấy mẫu phân tích các chất hữu cơ $\left(\mathrm{COD}, \mathrm{BOD}_{5}\right)$, chất rắn lơ lửng (TSS) và yếu tố vi sinh (fecal coliform). Các mẫu nước được phân tích tại Trung tâm Nghiên cứu Công nghệ môi trường và Quản lý Tài nguyên thiên nhiên, Trường Đại học Nông Lâm thành phố Hồ Chí Minh để xác định các thông số về chất lượng nước gồm $\mathrm{COD}, \mathrm{BOD}_{5}$, TSS và fecal coliform.

Bảng 4. Phương pháp phân tích chất lượng nước

\begin{tabular}{clll}
\hline TT & Chỉ tiêu & Phương pháp phân tích & Tiêu chuẩn \\
\hline 1 & pH & Điện cực & TCVN 6492-2000 \\
2 & BOD $_{5}$ & Winkler cải tiến & APHA 5210 B \\
3 & COD & Đun hoàn lưu kín & APHA 5220 C \\
4 & TSS & Sấy & APHA 2540 D \\
5 & Fecal coliform & MPN & TCVN 4882-2001 \\
\hline
\end{tabular}

\subsection{Phương pháp xử lý số liệu}

Số liệu thu thập được biểu diễn bởi giá trị trung bình (mean) và độ lệch chuẩn (SD). Quá trình xử lý thống kê và phân tích số liệu sử dụng các phần mềm Excel và SPSS 13.0 for Windows. Ngoài ra, phân tích thống kê ANOVA và LSD được áp dụng để phân biệt sự khác biệt thống kê có ý nghĩa giữa các nghiệm thức ở $\mathrm{P}<0,05$.

\section{KÊT QUẢ NGHIÊN CÚU VÀ THẢO LUẬN}




\subsection{Hiệu quả xử lý của mô hình dòng chảy thẳng đứng với tải nạp thủy lực 500 $\mathrm{mL} /$ phút $/ \mathrm{m}^{2}$}

Vai trò của thủy thực vật trong hệ thống đất ngập nước kiến tạo nhìn chung có hai tác động về mặt vật lý và hóa sinh. Theo Brix $(1994,1997)$ tác động về mặt vật lý gồm chống sự xói mòn trong hệ hống, tăng độ dẫn nước nhờ bộ rễ, giữ nhiệt trong mùa đông, và đặc biệt là tạo chỗ bám cho vi sinh vật để hình thành màng sinh học. Về mặt hóa sinh gồm tăng mức oxy hóa quanh rễ hòa tan nhờ khả năng
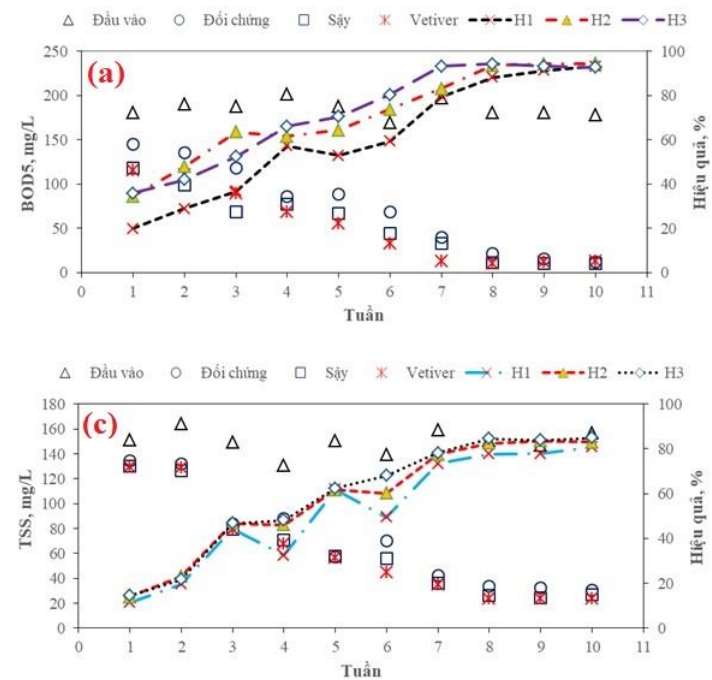

dẫn truyền oxy từ không khí, hấp thu muối dinh dưỡng và các chất gây ô nhiễm khác. Trong nghiên cứu này, hàm lượng của nước trước (đầu vào) và sau (đầu ra) xử lý của $\mathrm{BOD}_{5}, \mathrm{COD}, \mathrm{TSS}$ và fecal coliform của tải nạp thủy lực $\mathrm{T} 1$ được trình bày trong các Hình 4a-d. Nhìn chung, sự biến động hàm lượng $\mathrm{BOD}_{5}$ có $\mathrm{xu}$ hướng giảm dần theo thời gian và nhất là từ tuần thứ 7 đạt hiệu quả cao, đồng thời thỏa mãn Quy chuẩn kỹ thuật quốc gia chất lượng nước mặt QCVN 08-MT:2015/BTNMT sử dụng mục đích tưới tiêu nông nghiệp.
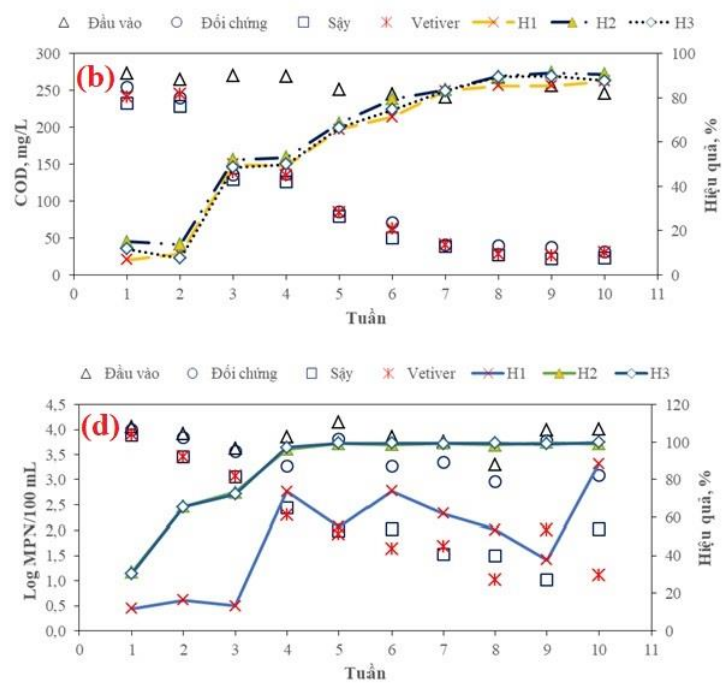

\section{Hình 4. Hàm lượng và hiệu quả xử lý (a) $\mathrm{BOD}_{5}$, (b) COD, (c) TSS và (d) fecal coliform trong thí nghiệm T1}

Đối với hàm lượng COD, kết quả nghiên cứu cho thấy sự giảm mạnh từ thời điểm tuần thứ 4 . Tuy nhiên, kết quả chỉ ra rằng mức độ đáp ứng tiêu chí dùng cho mục đích tưới tiêu, thủy lợi theo Quy chuẩn kỹ thuật quốc gia về chất lượng nước mặt (QCVN 08-MT:2015/BTNMT) ở thời gian sau 7 tuần vận hành. Riêng đối với hàm lượng TSS đã có dấu hiệu tốt hơn và có thể đáp ứng quy chuẩn chất lượng nước ở số liệu phân tích trong tuần thứ 6 . Ngoài ra, hiệu quả xử lý $\mathrm{BOD}_{5}, \mathrm{COD}$, TSS và fecal coliform trong thí nghiệm T1 $(\mathrm{HRT}=14,0$ giờ) được trình bày cụ thể trong các Hình $4 \mathrm{a}-\mathrm{d}$. Mức độ xử lý $\mathrm{BOD}_{5}$ trung bình lần lượt đối với bể đối chứng, sậy và vertiver là $60,7 \pm 26,7 \%, 71,1 \pm 20,6 \%$ và $72,0 \pm 22,4 \%$. Trong khi đó, hiệu quả loại bỏ COD lần lượt là $59,4 \pm 30,4 \%, \quad 63,8 \pm 29,7 \%$ và $60,9 \pm 30,9 \%$; và ngoài ra kết quả xử lý hàm lượng TSS tương ứng là $52,9 \pm 25,5 \%, 57,8 \pm 25,2 \%$ và $59,3 \pm 25,9 \%$. Kêt quả nghiên cứu còn chỉ rõ hiệu quả xử lý mức cao và đạt $>80 \%$ từ thời điểm tuần thứ 7 . Đặc biệt, hiệu quả xử lý đạt mức cao ở giai đoạn cuối với lần lượt đối với $\mathrm{BOD}_{5}, \mathrm{COD}, \mathrm{TSS}$ là $94,1 \pm 0,4 \%, 90,6 \pm 0,8 \%$ và $84,4 \pm 0,6 \%$. Có thể thấy vai trò xử lý chất hữu cơ trong hệ thống đất ngập nước kiến tạo chủ yếu là do vi sinh vật thực hiện (Akratos, 2007; Brix, 1997; Steer et al., 2002; Vymazal, 2002). Hiệu quả xử lý $\mathrm{BOD}_{5}, \mathrm{COD}$ có thể do sự có mặt số lượng cần thiết vi sinh vật trong hoạt động xử lý chất hữu cơ trong các nghiệm thức. Nhìn chung, quá trình xử lý các thông số ô nhiễm ổn định và đạt hiệu suất cao sau thời gian 50 ngày vận hành hệ thống. Đối với thông số vi sinh, hiệu quả loại bỏ đạt mức rất cao ở thời điểm sau 4 đến 5 tuần vận hành. Trong đó, đặc biệt ở thời gian tuần thứ 8-9 thể hiện hiệu suất đạt ngưỡng 99,9\% khả năng loại bỏ yếu tố mầm bệnh.

\subsection{Hiệu quả xử lý của mô hình dòng chảy thẳng đứng với tải nạp thủy lực 1000 $\mathrm{mL} / \mathrm{phút} / \mathrm{m}^{2}$}

Hàm lượng $\mathrm{TSS}, \mathrm{BOD}_{5}$ và $\mathrm{COD}$ của nước trước (đầu vào) và sau (đầu ra) xử lý với tải nạp thủy lực T2 được trình bày trong các Hình $5 \mathrm{a}-\mathrm{c}$. Có thể thấy, 
mức độ loại bỏ chất hữu cơ $\left(\mathrm{BOD}_{5}\right.$ và $\left.\mathrm{COD}\right)$ được thể hiện tính hiệu quả ở tuần thứ 5-10. Trong đó, sau thời gian 7 tuần vận hành có xu hướng gia tăng hiệu quả rõ rệt và thỏa mãn quy chuẩn kỹ thuật quốc gia về chất lượng nước mặt dùng cho tưới tiêu, thủy lợi.
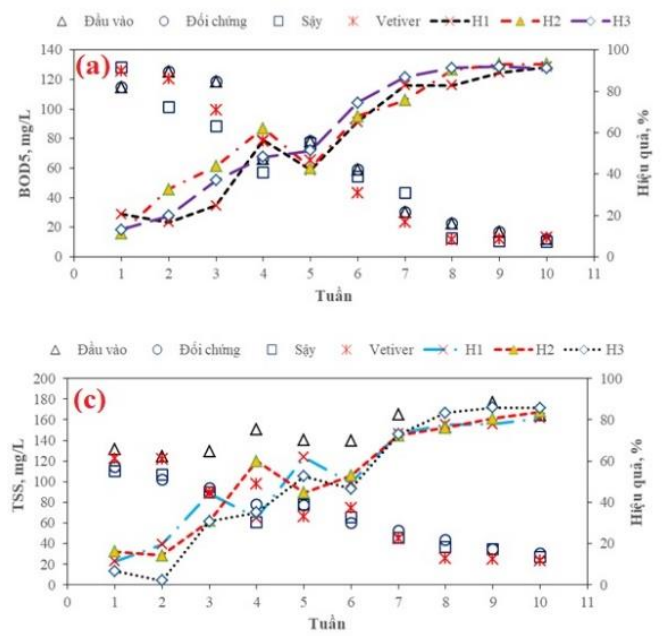

Sự biến thiên hàm lượng TSS có sự tương đồng với mức độ biến động hàm lượng chất hữu cơ. Ở vào giai đoạn tuần thứ 6 , hiệu quả xử lý thể hiện thông qua mức độ cao $(>80 \%)$ và cao nhất ở các tuần cuối cùng.
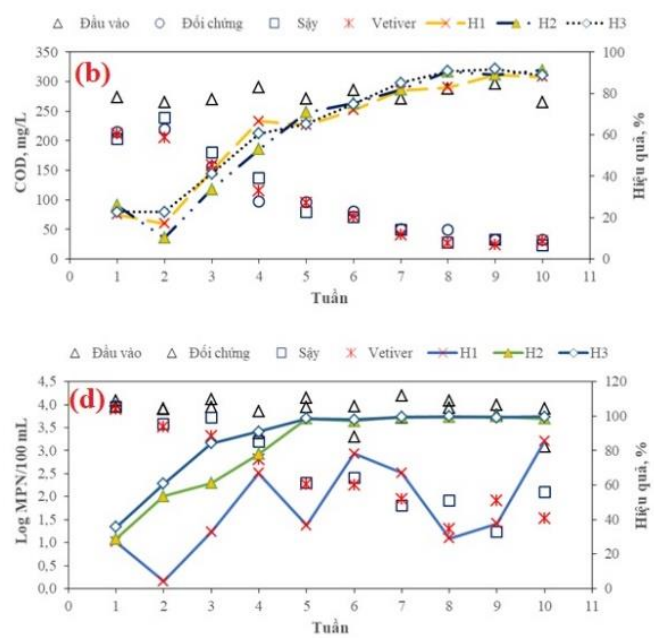

\section{Hình 5. Hàm lượng và hiệu quả xử lý (a) $\mathrm{BOD}_{5}$, (b) COD, (c) TSS và (d) fecal coliform trong thí nghiệm T2}

Hình 5a-c cho thấy chất lượng nước đầu vào cho thí nghiệm từ kênh $\mathrm{D}$ như đã đề cập ở trên có hàm lượng TSS, $\mathrm{BOD}_{5}, \mathrm{COD}$ vượt xa các thông số quy định cho nguồn nước tưới tiêu QCVN 08MT:2015/BTNMT. Tuy nhiên, hàm lượng sau xử lý của $\mathrm{TSS}, \mathrm{BOD}_{5}$ và $\mathrm{COD}$ xấp xỉ đạt các quy chuẩn làm nguồn nước tưới tiêu nông nghiệp. Riêng đối với các tuần 8-10, phần lớn các thông số chất lượng nước đều đạt ngưỡng giới hạn theo quy chuẩn. Một số công trình nghiên cứu đã ghi nhận rằng tuổi của hệ thống có tác động rất lớn đến hiệu quả xử lý của nó (Kadlec \& Knight, 1996; Prochaska et al., 2007; Verhoeven \& Meuleman, 1999; Wang et al., 2012). Thật vậy, tuổi cây càng cao thì hệ thống rễ càng phát triển, có thể làm gia tăng thời gian lưu nước và hiệu quả xử lý (Suliman et al., 2006). Hoạt động xử lý TSS, BOD 5 và $\mathrm{COD}$ ở tải nạp thủy lực T2 (HRT = 7,0 giờ) được trình bày trong Hình $5 \mathrm{a}-\mathrm{c}$. Quá trình loại bỏ chất ô nhiễm như TSS, $\mathrm{BOD}_{5}, \mathrm{COD}$ trong nghiệm thức trồng sậy là $53,2 \pm 26,0 \%$ cho TSS, $61,3 \pm 28,0 \%$ với $\mathrm{BOD}_{5}$ và $62,2 \pm 29,7 \%$ trường hợp COD; và trong khi ở lô trồng vertiver lần lượt với hiệu suất $50,2 \pm 31,6 \%, 60,5 \pm 30,7 \%$ và $64,3 \pm 27,1 \%$. Đối với hàm lượng fecal coliform cho thấy hiệu quả xử lý thấp nhất đạt $28,8 \%$ (sậy) và $35,6 \%$ (vertiver) và cao nhất lên tới $99,8 \%$ cho cả sậy và vertiver (Hình $5 \mathrm{~d}$ ). Ngoài ra, từ tuần thí nghiệm thứ 5 các nghiệm thức đã có kết quả xử lý tốt đối với fecal coliform với mức hiệu suất $>95 \%$.

\subsection{Hiệu quả xử lý của mô hình dòng chảy thẳng đứng với tải nạp thủy lực 1500 $\mathrm{mL} / \mathrm{phút} / \mathrm{m}^{2}$}

Hình $6 \mathrm{a}-\mathrm{c}$ cho thấy hàm lượng $\mathrm{BOD}_{5}, \mathrm{COD}$ và TSS ở đầu vào và đầu ra ở thí nghiệm với tải nạp thủy lực $\mathrm{T} 3$. Hàm lượng $\mathrm{BOD}_{5}, \mathrm{COD}$ và $\mathrm{TSS}$ ở đầu vào vượt hơn nhiều lần Quy chuẩn $\mathrm{QCVN}$ 08MT:2015/BTNMT đối với nước tưới tiêu nông nghiệp. Tuy nhiên, kết quả nghiên cứu đã có sự suy giảm rõ rệt các hàm lượng $\mathrm{TSS}, \mathrm{BOD}_{5}$ và $\mathrm{COD}$ ở các giá trị đầu ra. Gần đây, nhiều nghiên cứu về vai trò và tác động của cây trồng trong hệ thống đất ngập nước kiến tạo đã được thực hiện. Vai trò của cây trong việc làm gia tăng lượng vi sinh vật trong hệ thống so với hệ thống không trồng cây nhờ vào bộ rễ làm khu trú vi sinh vật đã được xác nhận. Sleytr et al. (2009) đã xác định thành phần vi sinh vật trong hệ thống có trồng cây khác với không trồng cây, cho thấy ảnh hưởng của bộ rễ lên thành phần quần xã vi sinh vật. Nghiên cứu sâu hơn về hoạt động sinh hóa của các quần thể vi sinh vật bám ở bộ rễ, Wang et al. (2012) đã ghi nhận hoạt động của vi sinh vật trong nghiệm thức có trồng mạnh hơn đối chứng không trồng cây.

Nhìn chung, về xu hướng cho thấy khả năng loại bỏ các chất hữu cơ như $\mathrm{BOD}_{5}, \mathrm{COD}$ và chất rắn (TSS) trong nguồn nước nhiễm bẩn gia tăng theo chuỗi thời gian, nhất là giai đoạn các tuần thứ 6-10. 
Trong đó, ở các tuần 8-10, thông số $\mathrm{BOD}_{5}$ và $\mathrm{COD}$ có giá trị nhỏ hơn giới hạn cho phép và đáp ứng Quy chuẩn kỹ thuật quốc gia nước mặt (Cột B1). Diễn
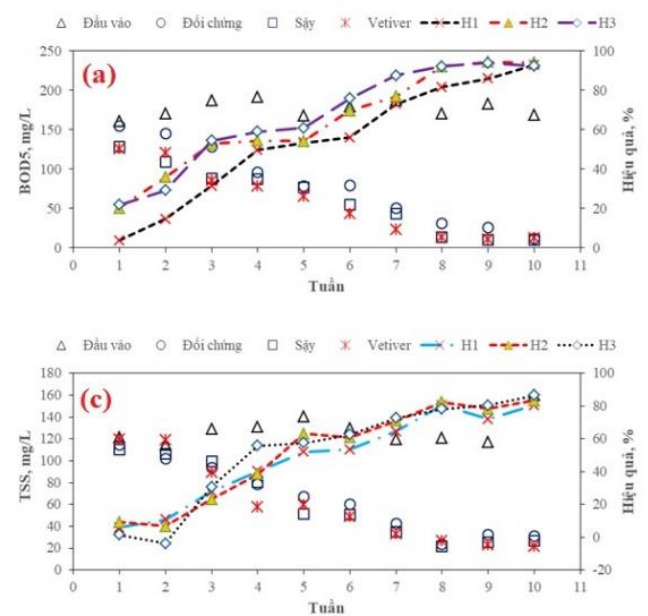

biến chi tiết hàm lượng và hiệu quả xử lý trong thí nghiệm T3 (ứng với $2160 \mathrm{~mm} /$ ngày) với các thông số được biểu diễn ở Hình 6a-c.
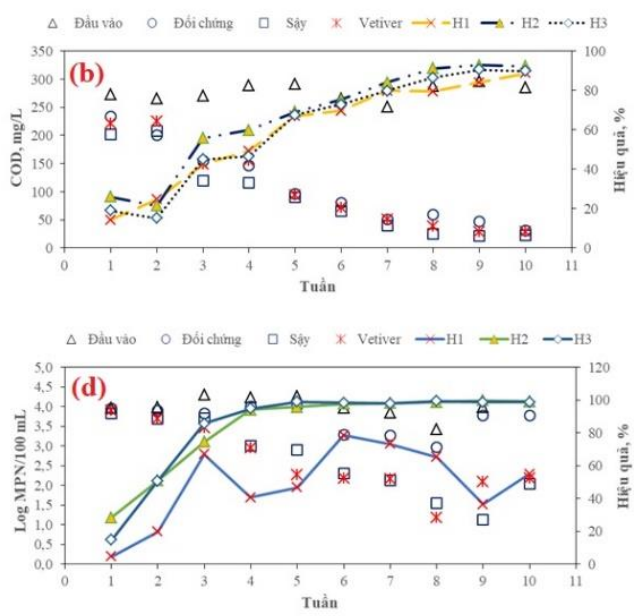

\section{Hình 6. Hàm lượng và hiệu quả xử lý (a) BOD, (b) COD, (c) TSS và (d) fecal coliform trong thí nghiệm T3}

Đối với hiệu quả xử lý $\mathrm{TSS}, \mathrm{BOD}_{5}, \mathrm{COD}$ và fecal coliform được trình bày cụ thể trong Hình $6 \mathrm{a}-$ d. Hiệu suất loại bỏ $\mathrm{BOD}_{5}, \mathrm{COD}$ và TSS trong nghiệm thức trồng sậy tuần tự là $64,5 \pm 25,5 \%$, $66,8 \pm 26,2 \%$ và $51,6 \pm 29,9 \%$ và ở nghiệm thức trồng vertiver tuần tự là $66,7 \pm 26,3 \%, 61,3 \pm 28,3 \%$ và $52,2 \pm 32,3 \%$. Nhìn chung, mức độ và hiệu quả xử lý thành phần ô nhiễm đạt mức cao (>90\%) ở giai đoạn tuần thứ $9-10$ (đối với $\mathrm{BOD}_{5}$ và $\mathrm{COD}$ ) và xấp xỉ $80 \%$ (đối với TSS). Liên quan đến hiệu quả xử lý fecal coliform dao động trong khoảng $28,4 \%$ đến $99,9 \%$ (sậy) và $14,8 \%$ đến $99,4 \%$ (vertiver). Từ thời điểm tuần thứ 5 , mức độ loại bỏ mầm bệnh đạt ngưỡng $>95 \%$ và đạt giá trị cực đại vào tuần thứ 9 và 10 (>99\%). Rõ ràng, điều này cho thấy tính hiệu quả cao của hệ thống trong việc làm sạch nguồn nước bị ô nhiễm thành phần vi sinh.

\subsection{So sánh, đánh giá hiệu quả xử lý giữa các tải nạp thủy lực và các yếu tố liên quan}

Theo thống kê ANOVA (yếu tố cây và yếu tố tải nạp) cho thấy hiệu quả loại bỏ $\mathrm{BOD}_{5}$ và $\mathrm{COD}$ là không có sự khác biệt về khả năng xử lý giữa các loại cây thí nghiệm $(\mathrm{P}>0,05)$. Kết quả so sánh giữa hai loài cây sậy và vertiver thể hiện hiệu quả xử lý tương đương, điều này có thể do tuổi của cây còn nhỏ nên mức độ tác động chưa rõ rệt. Trái lại, tải nạp thủy lực có tác động rõ rệt đến hiệu quả xử lý $\mathrm{BOD}_{5}$ và $\mathrm{COD}(\mathrm{P}<0,05)$. Đồng thời, phân tích ANOVA cũng cho thấy các yếu tố (cây và tải nạp thủy lực) chưa thể hiện rõ tác động tương tác về ý nghĩa thống kê $(\mathrm{P}>0,05)$ lên hiệu quả xử lý. Như vậy, sự thay đổi của yếu tố này không làm thay đổi hiệu quả xử lý hay nói cách khác các yếu tố có khuynh hướng độc lập.

Bảng 5. So sánh hiệu quả xử lý BOD5, COD, TSS (\%) giữa các tải nạp (T1, T2 và T3)

\begin{tabular}{lcrrr}
\hline Thông số & Tải nạp & Trung bình & Thấp nhất & Cao nhất \\
\hline \multirow{2}{*}{ BOD $_{5}$} & T1 & $90,0 \pm 5,8^{\mathrm{a}}$ & 80,9 & 95,3 \\
& T2 & $86,2 \pm 7,1^{\mathrm{a}}$ & 75,4 & 94,0 \\
& $\mathrm{~T} 3$ & $66,8 \pm 10,3^{\mathrm{b}}$ & 44,3 & 80,5 \\
\multirow{2}{*}{$\mathrm{COD}$} & $\mathrm{T} 1$ & $82,9 \pm 7,3^{\mathrm{c}}$ & 66,9 & 90,5 \\
& $\mathrm{~T} 2$ & $78,4 \pm 3,8^{\mathrm{c}}$ & 71,4 & 82,8 \\
& $\mathrm{~T} 3$ & $71,9 \pm 6,3^{\mathrm{d}}$ & 62,9 & 82,5 \\
\multirow{2}{*}{ TSS } & T1 & $82,4 \pm 2,9^{\mathrm{e}}$ & 77,9 & 86,9 \\
& T2 & $71,7 \pm 7,4^{\mathrm{f}}$ & 61,1 & 81,6 \\
& T3 & $66,0 \pm 5,3^{\mathrm{g}}$ & 57,3 & 73,5 \\
\hline
\end{tabular}

Chú thích: Các giá trị trong cùng một cột chỉ cần có một mẫu tụ giống nhau sẽ không khác nhau có ý nghĩa về mặt thống kê $(P>0,05)$. 
So sánh hiệu quả xử lý $\mathrm{BOD}_{5}$ giữa các nghiệm thức T1, T2, T3 (Bảng 5) cho thấy tải nạp thủy lực T3 khác biệt có ý nghĩa thống kê với các tải nạp T1 và $\mathrm{T} 2(\mathrm{P}<0,05)$. Xét về hiệu quả xử lý thì tải nạp $\mathrm{T} 1$ đạt cao nhất $(90,0 \pm 5,8 \%)$, tuy nhiên do tải nạp T1 không khác biệt so với tải nạp T2, do đó xét về hiệu quả kinh tế thì tải nạp T2 là tối ưu khi áp dụng để xử lý chỉ tiêu $\mathrm{BOD}_{5}$. Tương tự như chỉ tiêu $\mathrm{BOD}_{5}$, kết quả cho thấy hiệu quả xử lý $\mathrm{COD}$ có sự khác biệt thống kê giữa tải nạp $\mathrm{T} 3$ với các tải nạp $\mathrm{T} 1$ và $\mathrm{T} 2$ $(\mathrm{P}<0,05)$. Xem xét hiệu quả xử lý trung bình giữa các tải nạp thủy lực thì tải nạp $\mathrm{T} 1$ là cao nhất $(82,9 \pm 7,3 \%)$, trong khi đó hiệu quả xử lý ở tải nạp $\mathrm{T} 2$ là $78,4 \pm 3,8 \%$. Tuy nhiên, giữa hai tải nạp $\mathrm{T} 1$ và T2 không có khác biệt có ý nghĩa, do đó xét về mặt hiệu quả kinh tế tải nạp T2 sẽ tối ưu. Đối với chỉ tiêu TSS, phân tích ANOVA (yếu tố cây và tải nạp) cho thấy không có sự khác biệt thống kê về hiệu quả xử lý TSS giữa các loại cây $(\mathrm{P}>0,05)$. Trái lại, yếu tố tải nạp thủy lực có tác động rõ rệt đến hiệu quả xử lý hàm lượng TSS $(\mathrm{P}<0,05)$. Khi so sánh hiệu quả xử lý TSS cho thấy có sự khác biệt có ý nghĩa giữa 3 tải nạp thủy lực. Trong đó, tải nạp T1 có hiệu quả xử lý đạt cao nhất với kết quả ở mức $82,4 \pm 2,9 \%$.

Đánh giá hiệu quả xử lý hàm lượng fecal coliform cho thấy sự khác biệt giữa các nghiệm thức trồng cây và đối chứng $(\mathrm{P}<0,05)$. Tuy nhiên, kết quả không cho thấy có sự khác biệt có ý nghĩa thống kê giữa hai loại cây trồng là sậy và vertiver $(\mathrm{P}>0,05)$. Nhìn chung, sự loại bỏ đối với yếu tố vi sinh đạt hiệu quả cao và đặc biệt giá trị cực đại $(99,9 \%)$ đối với cả sậy và vertiver. So sánh hiệu quả xử lý fecal coliform giữa các nghiệm thức chỉ ra hiệu quả loại bỏ thành phần vi sinh có sự khác biệt rõ rệt. Từ đó, cho thấy tác động tích cực của mô hình đất ngập nước kiến tạo sử dụng cỏ sậy và vertiver trong việc áp dụng xử lý yếu tố mầm bệnh đối với nguồn nước bị ô nhiễm.

Bảng 6. So sánh hiệu quả xử lý fecal coliform (\%) giữa các nghiệm thức

\begin{tabular}{lrrr}
\hline $\begin{array}{l}\text { Nghiệm } \\
\text { thức }\end{array}$ & Trung bình & $\begin{array}{r}\text { Thấp } \\
\text { nhất }\end{array}$ & $\begin{array}{r}\text { Cao } \\
\text { nhất }\end{array}$ \\
\hline Đối chứng & $47,9 \pm 25,1^{\mathrm{h}}$ & 4,3 & 88,3 \\
Sậy & $83,8 \pm 23,6^{\mathrm{i}}$ & 28,4 & 99,9 \\
Vertiver & $85,5 \pm 23,8^{\mathrm{i}}$ & 14,8 & 99,9 \\
\hline
\end{tabular}

Chú thích: Các giá tri trong cùng môt côt chỉ cần có môt mẫu tư giống nhau sẽ không khác nhau có ý nghĩa về mặt thống kê $(P>0,05)$.

Như vậy, khi tải nạp thủy lực gia tăng, như được mong đợi, hiệu quả xử lý đã suy giảm đáng kể. Hiệu quả loại bỏ các chất gây ô nhiễm ở tải nạp T1 luôn cao hơn các tải nạp T2 và T3. Hoạt động xử lý của tải nạp $\mathrm{T} 1$ đạt khá cao đối với $\mathrm{BOD}_{5}, \mathrm{COD}$ và $\mathrm{TSS}$ trong các bể thí nghiệm có trồng cây. Kết quả có thể đạt $90 \%$ cho $\mathrm{BOD}_{5}$, lớn hơn $80 \%$ cho COD và TSS (Bảng 5). Các kết quả xử lý có thể so sánh với các tác giả khác về $\mathrm{BOD}_{5}, \mathrm{COD}$ và $\mathrm{TSS}$ và đạt hiệu quả tốt (Brix \& Arias, 2005; Vymazal, 2002, 2009; Zurita, 2009). Brix và Arias (2005) đã tổng kết hiệu quả xử lý nước thải sinh hoạt bằng hệ thống đất ngập nước dòng chảy thẳng đứng trồng sậy tại Đan Mạch. Theo đó, hiệu quả xử lý lần lượt đối với $\mathrm{BOD}_{5}$ là $92 \%$ và TSS là $91 \%$. Tương tự, theo Zurita (2009), hiệu quả loại bỏ chất ô nhiễm trong nước thải sinh hoạt ở dòng chảy thẳng đứng là $80 \%$ cho $\mathrm{BOD}_{5}$ và COD. Morari (2009) sử dụng dòng chảy thẳng đứng xử lý nước thải đô thị tại Ý (tính chất nước thải tương tự trong nghiên cứu này) phục vụ cho tái sử dụng vào mục đích tưới tiêu cho thấy hiệu quả xử lý $>86 \%$ đối với $\mathrm{BOD}_{5}$ và $\mathrm{COD}$. Đặc biệt, nhóm tác giả thực hiện tại Việt Nam (Dan et al., 2011) cũng sử dụng dòng chảy thẳng đứng xử lý nước thải pha lẫn nước thải chăn nuôi và nước thải sinh hoạt. Theo đó, hiệu quả xử lý trung bình đối với $\mathrm{COD}, \mathrm{BOD}_{5}$ tương ứng lần lượt $68 \%$ và $72 \%$. Như vậy, so với các nghiên cứu khác cho thấy hiệu quả chuyển hóa chất ô nhiễm cao nhờ vào đặc tính của dòng chảy đứng (Kadlec \& Wallace, 2009). Đặc biệt, dòng chảy đứng được áp dụng trong nghiên cứu với dòng chảy suốt từ trên xuống dưới và chính điều này đã góp phần tạo điều kiện tốt để oxy có thể khuếch tán vào toàn bộ hệ thống. Mặt khác, điều kiện khí hậu nóng ẩm, nhiệt độ cao của miền Nam Việt Nam góp phần làm cho hiệu quả xử lý cao hơn ở các nước ôn đới.

Đánh giá thêm ảnh hưởng của các tải nạp thủy lực trong nghiên cứu này, loại dòng chảy thẳng đứng không bão hòa với dòng chảy xuyên suốt từ trên xuống. Các tải nạp thủy lực được vận hành trong nghiên cứu là 500,1000 và $1500 \mathrm{~mL} /$ phút $/ \mathrm{m}^{2}$, tương đương 720,1440 và $2160 \mathrm{~mm} /$ ngày. Thông thường tải nạp cao hơn sẽ đưa đến hiệu quả xử lý thấp hơn do thời gian lưu nước trong hệ thống ngắn hơn; nói cách khác, do thời gian nước bị ô nhiễm tiếp xúc với các tác nhân xử lý trong hệ thống đất ngập nước kiến tạo như lớp vật liệu lọc, màng sinh học và sự hấp thu của bộ rễ cây sẽ ngắn hơn. Thật vậy, hiệu quả xử lý $\mathrm{BOD}_{5}, \mathrm{COD}$, TSS của tải nạp T1 $\left(500 \mathrm{~mL} / \mathrm{phút}^{2} / \mathrm{m}^{2}\right)$ đạt cao nhất so với các tải nạp T2 và T3. Chính vì tải nạp thủy lực quyết định thời gian lưu nước, do vậy, tải nạp là yếu tố cho thấy tác động có ý nghĩa thống kê $(\mathrm{P}<0,05)$ lên hiệu quả xử lý các chất hữu cơ được xem xét trong nghiên cứu. Trong công trình ứng dụng công nghệ đất ngập nước kiến tạo tại Cần 
Thơ, nơi có cùng điều kiện sinh thái miền Nam Việt Nam, Dan et al. (2011) sử dụng dòng chảy thẳng đứng và cây điên điển (Sesbanian sesba), với kết luận tải nạp thủy lực lớn nhất $320 \mathrm{~mm} /$ ngày đã không cho hiệu quả xử lý tốt hơn các tải nạp thấp. So sánh kết quả cho thấy tải nạp thủy lực T1 trong nghiên cứu này có hiệu quả xử lý tương đương. Hơn nữa, Kadlec và Wallace (2009) đã xác định ưu điểm của dòng chảy đứng là sự dẫn truyền oxy vào hệ thống tốt hơn các dòng chảy khác. Điều này có thể được giải thích bởi kiểu dòng chảy thẳng đứng có hiệu quả dẫn truyền oxy hòa tan vào toàn hệ thống tốt và góp phần oxy hóa các chất ô nhiễm trong nước.

\section{KẾT LUẦN}

Kết quả nghiên cứu cho thấy hiệu quả xử lý khá cao các chất hữu cơ $\left(\mathrm{BOD}_{5}, \mathrm{COD}\right)$ của hệ thống đất ngập nước kiến tạo sử dụng một số loài thực vật phổ biến (sậy và vertiver). Quá trình so sánh giữa các tải nạp thủy lực: $500 \mathrm{~mL} /$ phút $/ \mathrm{m}^{2}, 1000 \mathrm{~mL} / \mathrm{phút} / \mathrm{m}^{2}$, $1500 \mathrm{~mL} /$ phút $/ \mathrm{m}^{2}$ chỉ ra tải nạp $500 \mathrm{~mL} / \mathrm{phút}^{2} / \mathrm{m}^{2}$ (HRT=14,0 giờ) có hiệu quả xử lý cao nhất và chất lượng nước sau xử lý đạt QCVN 08MT:2015/BTNMT (Cột B1-dùng cho tưới tiêu nông nghiệp). Các kết quả cũng chỉ ra rằng việc xử lý các chất hữu cơ dựa vào vai trò của vi sinh vật trong hệ thống đất ngập nước kiến tạo. Kết quả so sánh giữa hai loài cây sậy và vertiver thể hiện hiệu quả xử lý tương đương, điều này có thể do tuổi của cây còn nhỏ nên mức độ tác động chưa rõ rệt. Tuy nhiên, vai trò của các loại cây trồng được thể hiện rõ nét thông qua hoạt động làm giảm đáng kể hàm lượng vi sinh fecal coliform trong các thí nghiệm $(\mathrm{P}<0,05)$. Hạn chế của nghiên cứu chỉ mới thực hiện đánh giá hiệu quả xử lý trong thời gian ngắn nên chưa thể tối đa hóa hiệu quả xử lý các chất ô nhiễm.

\section{TÀI LIỆU THAM KHẢO}

Aboubacar, S., Mohamed, R., Jamal, A., Omar A. \& Samira, E. (2018). Exploitation of Phragmites australis (Reeds) in filter basins for the treatment of wastewater. Journal of Environmental Science and Technology, 11(2), 56-67. DOI: 10.3923/jest.2018.56.67

Abou-Elela, S.I. \& Hellal M.S. (2012). Municipal wastewater treatment using vertical flow constructed wetlands planted with Canna, Phragmites and Cyprus. Ecological Engineering, 47, 209-213. https://doi.org/10.1016/j.ecoleng.2012.06.044

Almuktar, S.A.A.A.N., Abed, S.N., \& Scholz, M. (2018). Wetlands for wastewater treatment and subsequent recycling of treated effluent: a review. Environmental Science and Pollution
Research, 25(24), 23595-23623. DOI: 10.1007/s11356-018-2629-3

Arias, C.A., Del Buba, M., \& Brix, H., (2001). Phosphorus removal by sand for use as media in subsurface flow constructed reed bed. Water Research, 35, 1159-1168. DOI: 10.1016/s00431354(00)00368-7

Badejo, A.A., Omole, D.O. \& Ndambuki., J.M. (2018). Municipal wastewater management using Vetiveria zizanioides planted in vertical flow constructed wetland. Applied Water Science, 8, 110. https://doi.org/10.1007/s13201-018-0756-0

Brix, H. (1994). Functions of macrophytes in constructed wetlands. Water Science \& Technology, 29(4), 71-78. https://doi.org/10.2166/wst.1994.0160

Brix, H. (1997). Do macrophytes play a role in constructed treatment wetlands? Water Science \& Technology, 35, 11-17. https://doi.org/10.1016/S0273-1223(97)00047-4

Brix, H., \& Arias, A.C. (2005). The use of vertical flow constructed welands for on-site treatment of domestic wastewater: New Danish guidelines. Ecological Engineering. 25, 491-500. https://doi.org/10.1016/j.ecoleng.2005.07.009

Dallas, S., Scheffe, B., \& Ho, G. (2004). Reedbeds for greywater treatment-case study in Santa Elena-Monteverde, Costa Rica, Central America. Ecological Engineering, 23, 55-61. https://doi.org/10.1016/j.ecoleng.2004.07.002

Dan, T.H., Quang, L.N., Chiem, N.H., \& Brix, H. (2011). Treatment of high-strength wastwater in tropical constructed wetlands planted with Sesbania sesban: horizontal subsurface flow versus downflow. Ecological Engineering, 37(5), 711-720. DOI: 10.1016/j.ecoleng.2010.07.030

Danh, L.T., Truong, P., Mammucari, R., Tran, T., \& Foster, N. (2009). Vetiver grass, Vetiveria zizanioides: a choice plant for phytoremediation of heavy metals and organic waster. International Journal of Phytoremediation, 11, 664-691. https://doi.org/10.1080/15226510902787302

Datta, R., Das, P., Smith, S., Punamiya, P., Ramanthan, D.M., Reddy, R., \& Sarkar, D. (2013). Phytoremediation potential of vetiver grass (Vetiveria zizanioides (L) for tetracycline. International Journal of Phytoremediation, 15, 343-351. DOI: 10.1080/15226514.2012.702803

Dudai, N., Putievsky, E., Chaimovitch, D., \& BenHur, M. (2006). Growth management of vetiver (Vetiveria zizanioides) under Mediterranean conditions. Journal of Environmental Management, 81, 63-71. DOI: 10.1016/j.jenvman.2005.10.014

Effendi, H., Delis, P.C., Krisanti, M., \& Hariyadi, S. (2015). The performance of nile tilapia 
(Oreochromis niloticus) and vetiver grass (Vetiveria zizanioides) concurrently cultivated in aquaponic system. Advances in Environmental Biology, 9(24), 382-388.

ElZein, Z., Abdou, A., \& Abd ElGawad, I. (2016). Constructed wetlands as a sustainable wastewater treatment method in communities. Procedia Environmental Sciences, 34, 605-617. https://doi.org/10.1016/j.proenv.2016.04.053

Havens, K.J., Berquist, H. \& Priest, W.I. (2003). Common reed grass, Phragmites australis, expansion into constructed wetlands: Are we mortgaging our wetland future? Estuaries, 26, 417-422. https://doi.org/10.1007/BF02823718

Indrayatie, E.R., Utomo, W.H., ,Handayanto E., \& Anderson, C.W.N. (2013). The use of vetiver (Vetiveria zizanioides L.) for then remediation of wastewater discharged from tapioca factories. International Journal of Environment and Waste Management, 12(1), 1-16. DOI: 10.1504/IJEWM.2013.054776

Kadlec, R.H., \& Knight, R. (1996). Treatment Wetlands. CRC Press.

Kadlec R.H., \& Wallace S.D. (2009). Treatment Wetlands. CRC Press/Lewis Pucblishers, Boca Raton, FL.

Katarzyna, S., \& Magdalena, H.G. (2017). The use of constructed wetlands for the treatment of industrial wastewater. Journal of Water and Land Development. 34, 233-240. DOI: 10.1515/jwld-2017-0058

Lê Diễm Kiều, Nguyễn Minh Đạt, Nguyễn Xuân Lộc, Phạm Quốc Nguyên, Nguyễn Văn Công, \& Ngô Thụy Diễm Trang. (2018). Khả năng xử lý nước thải ao nuôi thâm canh cá tra (Pangasianodon hypophthamus) của hệ thống đất ngập nước kiến tạo dòng chảy mặt liên tục kết hợp với cỏ mồm mở (Hymenachne acutigluma). Tạp chí Nông nghiệp và Phát triển nông thôn, 5, 103-110.

Lê Hoàng Việt, Lê Thị Chúc Ly, Cao Thị Kim Ngọc, \& Nguyễn Võ Châu Ngân. (2017). Sử dụng đất ngập nước xử lí nước thải sinh hoạt và tạo cảnh quan. Tạp chi khoa học Trưòng Đại họ Su phàm TP. Hồ Chí Minh, 14(3), 162-175.

Licata, M., Tuttolomondo, T., Leto, C., La Bella, S., \& Virga, G. (2017). The use of constructed wetlands for the treatment and reuse of urban wastewater for the irrigation of two warm-season turfgrass species under Mediterranean climatic conditions. Water Science \& Technology, 76(2), 459-470. DOI: 10.2166/wst.2017.221

Lu, X., Kruatrachue, M., Pokethitiyook, P. \& Homyok, K. (2004). Removal of Cadmium and Zinc by Water Hyacinth, Eichhornia crassipes. ScienceAsia. 30, 93-103. DOI: 10.2306/scienceasia1513-1874.2004.30.093
Marecos, D.M.H., \& Albuquerque, A. (2010). Analysis of constructed wetland performance for irrigation reuse. Water Science \& Technology, 61(7), 1699-705. DOI: 10.2166/wst.2010.063

Maurizio, B., Gabriele, B., Santamaria, G., \& Giardini, L. (2001). A constructed surface flow wetland for treating agricultural waste waters. Water Science \& Technology, 44(11-12), 523-30. https://doi.org/10.2166/wst.2001.0875

Mirco, M. \& Attilio, T. (2013). Evapotranspiration from pilot-scale constructed wetlands planted with Phragmites australis in a Mediterranean environment. Journal of Environmental Science and Health, 48(5), 568-580. DOI: 10.1080/10934529.2013.730457

Morari, L.G. (2009). Municipal wastewater treatment with vertical flow constructed wetlands for irrigation reuse. Ecological Engineering, 35(5), 643-653. DOI: 10.1016/j.ecoleng.2008.10.014

Nguyễn Hoàng Ánh, Nguyễn Phan Thùy Linh, \& Trần Thế Loãn. (2014). Kiểm soát ô nhiễm nước tại Việt Nam - Cơ hội và thách thức. Tạp chí Môi trường, Chuyên đề I, 3-6.

Nguyễn Mạnh Khải, Nguyễn Thị Huyền Trang, Nguyễn Thùy Linh, Chu Anh Đào, Phạm Mạnh Cổn, \& Nguyễn Thị Nga. (2012). Nghiên cứu chất lượng nước sông Nhuệ khu vực Hà Nội. Tạp chí khoa học Đại học Quốc gia Hà Nội, 28(4S), 111-117.

Nguyễn Trần Khánh, Văn Phạm Đăng Trí, Nguyễn Thụy Kiều Diễm, \& Trần Thị Lệ Hằng. (2015). Công tác quản lý nguồn tài nguyên nước mặt trong sản xuất nông nghiệp vùng ven biển Đồng bằng Sông Cửu Long dưới tác động của biến đổi khí hậu. Tạp chi Khoa học Đại học Cần Tho, Số Môi trường và Biến đổi khí hậu, 159-166.

Phạm Ngọc Hoà. (2018). Nghiên cứu ứng dụng công nghệ đất ngập nước kiến tạo sử dụng nhóm thực vật Green Roof cho mục đích tái sinh nước thải sinh hoạt. Tạp chí Khoa hoc và Công nghệ Đại hoc Đà Nắng, 5(126), 53-57.

Prochaska, C.A., Zouboulis, A.I., \& Eskridge, K.M. (2007). Performance of pilot-scale vertical-flow constructed wetlands, as affected by season, substrate, hydraulic load and frequency of application of simulated urban sewage. Ecological Engineering, 31, 57-66. DOI: 10.1016/j.ecoleng.2007.05.007

Roongtanakiat, N. \& Chairoj, P. (2001). Uptake Potential of Some Heavy Metals by Vetiver Grass. Kasetsart Journal - Natural Science, 35, $46-50$.

Seroja, R., Effendi, H. \& Hariyadi, S. (2018). Tofu wastewater treatment using vetiver grass (Vetiveria zizanioides) and zeliac. Applied Water Science, 8(2). https://doi.org/10.1007/s13201018-0640-y 
Sleytr, K., Tietz, A., Langergraber, G., Haberl, R., \& Sessitsch, A. (2009). Diversity of abundant bacteria in subsurface vertical flow constructed wetlands. Ecological Engineering, 35, 10211025. DOI: 10.1016/j.ecoleng.2008.11.005

Steer, D., Fraser, L., Boddy, J., \& Seibert, B. (2002). Efficiency of small constructed wetlands for subsurface treatment of single-family domestic effluent. Ecological Engineering, 18, 429-440. DOI: $10.1016 / S 0925-8574(01) 00104-5$

Suliman, F., French, H.K., Haugen, L.E., \& Sovik, A.K. (2006). Change in flow and transport patterns in horizontal subsurface flow constructed wetlands as a result of biological growth. Ecological Engineering, 27, 124-133. https://doi.org/10.1016/j.ecoleng.2005.12.007

Truong, P.N., Foong, Y.K., Guthrie, M., \& Hung, Y.T. (2010). Phytoremediation of heavy metal contaminated soils and water using vetiver grass. In Environmental Bioengineering (pp. 233-275). Humana Press, Totowa, NJ. DOI: 10.1007/9781-60327-031-1_8

Verhoeven, J.T.A., \& Meuleman, A.F.M. (1999). Wetlands for wastewater treatment: opportunities and limitations. Ecological Engineering, 12, 512. https://doi.org/10.1016/S09258574(98)00050-0
Vymazal, J. (2002). The use of subsurface constructed wetlands for wastewater in Czech Republic: 10 years experience. Ecological Engineering, 18, 633-646. https://doi.org/10.1016/S0925-8574(02)00025-3

Vymazal, J. (2009). The use of constructed wetlands with horizontal sub-surface flow for various types of wastewater. Ecological Engineering, 35, $1-17$. https://doi.org/10.1016/j.ecoleng.2008.08.016

Vymazal, J. (2010). Constructed Wetlands for Wastewater Treatment. Water, 2, 530-549. DOI: 10.3390/w2030530

Wang, R., Baldy, V., Perissol, C., \& Korboulewsky, N. (2012). Influence of plants on microbial activity in a vertical dowflow wetland system treating waste activated sludge with high organic matter concentrations. Journal of Environmental Management, 95 158-164. https://doi.org/10.1016/j.jenvman.2011.03.021

Zurita, F.D.A. (2009). Treatment of domestic wastwater and production of commercial flower. Ecological Engineering. 35(5), 861-869. https://doi.org/10.1016/j.ecoleng.2008.12.026 